\title{
Characterization of sulfur oxidizing bacteria related to biogenic sulfuric acid corrosion in sludge digesters
}

Bettina Huber, Bastian Herzog, Jörg E. Drewes ${ }^{*}$, Konrad Koch and Elisabeth Müller

\begin{abstract}
Background: Biogenic sulfuric acid (BSA) corrosion damages sewerage and wastewater treatment facilities but is not well investigated in sludge digesters. Sulfur/sulfide oxidizing bacteria (SOB) oxidize sulfur compounds to sulfuric acid, inducing BSA corrosion. To obtain more information on BSA corrosion in sludge digesters, microbial communities from six different, BSA-damaged, digesters were analyzed using culture dependent methods and subsequent polymerase chain reaction denaturing gradient gel electrophoresis (PCR-DGGE). BSA production was determined in laboratory scale systems with mixed and pure cultures, and in-situ with concrete specimens from the digester headspace and sludge zones.

Results: The SOB Acidithiobacillus thiooxidans, Thiomonas intermedia, and Thiomonas perometabolis were cultivated and compared to PCR-DGGE results, revealing the presence of additional acidophilic and neutrophilic SOB. Sulfate concentrations of 10-87 mmol/L after 6-21 days of incubation (final pH 1.0-2.0) in mixed cultures, and up to $433 \mathrm{mmol} / \mathrm{L}$ after 42 days (final $\mathrm{pH}<1.0$ ) in pure $A$. thiooxidans cultures showed huge sulfuric acid production potentials. Additionally, elevated sulfate concentrations in the corroded concrete of the digester headspace in contrast to the concrete of the sludge zone indicated biological sulfur/sulfide oxidation.
\end{abstract}

Conclusions: The presence of SOB and confirmation of their sulfuric acid production under laboratory conditions reveal that these organisms might contribute to BSA corrosion within sludge digesters. Elevated sulfate concentrations on the corroded concrete wall in the digester headspace (compared to the sludge zone) further indicate biological sulfur/sulfide oxidation in-situ. For the first time, SOB presence and activity is directly relatable to BSA corrosion in sludge digesters.

Keywords: Acid attack, Concrete corrosion, Sludge digester, Sulfur oxidizing bacteria, Thiobacillus, Biogenic sulfuric acid, Sulfate reducing organisms

\section{Background}

Microbial deterioration of concrete by biogenic sulfuric acid (BSA) is a serious and common problem in wastewater treatment facilities. Worldwide, maintenance and retrofitting of degraded concrete structures costs several billions of dollars every year [1]. BSA corrosion is a multistage process of sulfur/sulfate reducing (SRB) and sulfur/sulfide oxidizing bacteria ( $\mathrm{SOB}$ ). The first, anaerobic, step occurs when SRB reduce sulfate and other oxidized sulfur compounds to hydrogen sulfide $\left(\mathrm{H}_{2} \mathrm{~S}\right)$

\footnotetext{
* Correspondence: jdrewes@tum.de

Chair of Urban Water Systems Engineering, Technical University of Munich, Am Coulombwall 3, 85748 Garching, Germany
}

[2]. $\mathrm{H}_{2} \mathrm{~S}$ volatilizes and dissolves in the moist concrete surface [3]. The initial $\mathrm{pH}$ of concrete is approximately 12.0 , a value hardly allowing microbial growth [3]. $\mathrm{H}_{2} \mathrm{~S}$, $\mathrm{CO}_{2}$ and other gases with acidic properties abiotically decrease the $\mathrm{pH}$ to values around 9.0 enabling the colonization of neutrophilic sulfur oxidizing bacteria (NSOB) such as Thiobacillus spp. and Thiomonas spp. [4]. These NSOB, oxidize $\mathrm{H}_{2} \mathrm{~S}$ and other reduced sulfur compounds to sulfuric acid $\left(\mathrm{H}_{2} \mathrm{SO}_{4}\right)$ and polythionic acids thus lowering the $\mathrm{pH}$ to around 3.5-5.0 [5]. At pH 5.0 and below, acidophilic sulfur oxidizing bacteria (ASOB) such as Acidithiobacillus thiooxidans, continue sulfur oxidation by producing high amounts of sulfuric acid that decreases the $\mathrm{pH}$ to $1.0-2.0[6,7] . \mathrm{H}_{2} \mathrm{SO}_{4}$ 
reacts with the cement matrix leading to the formation of gypsum $\left(\mathrm{CaSO}_{4} \cdot 2 \mathrm{H}_{2} \mathrm{O}\right)$ and ettringite $\left(3 \mathrm{CaO} \cdot \mathrm{Al}_{2} \mathrm{O}_{3}\right.$. $\left.3 \mathrm{CaSO}_{4} \cdot 32 \mathrm{H}_{2} \mathrm{O}\right)$ [8]. These expansive sulfate salts lead to internal cracks in the concrete and finally to structural failure [9]. Corrosion rates of several millimeters per year are reported for sewer pipes [10]. BSA corrosion, although well described in sewer pipes, is hardly investigated in sludge digesters where anaerobic conditions enable the growth of SRB and $\mathrm{H}_{2} \mathrm{~S}$ production [11, 12], but the occurrence of aerobic SOB, comes unexpected.

To better understand concrete and BSA corrosion in sludge digesters, this study identified BSA-related bacteria and evaluated their corrosion potential. Biofilm from concrete surfaces, potentially containing SOB, was collected in the headspace of six different full-scale digesters at wastewater treatment plants in Germany. The digesters operated for 25 to 52 years and showed characteristic corrosion damage patterns (Fig. 1a). Conventional cultivation techniques showed the ability of the microbial biofilm community to produce sulfuric acid under controlled laboratory conditions. SOB, isolated and identified from enriched biofilm cultures, achieved a $\mathrm{pH}$ drop and sulfuric acid production thus indicating BSA corrosion potential. To characterize the community composition in-depth, polymerase chain reaction denaturing gradient gel electrophoresis (PCRDGGE) was applied while in-situ sulfate measurements in concrete samples taken from the digester headspace and sludge zone provided further information on SOB activity.

\section{Materials}

\section{Sample collection}

Biofilm samples were collected from corroded headspace concrete surfaces of six different full-scale digesters at wastewater treatment plants in Germany (A-F). Detailed information about the digesters is provided in Table 1. Biofilms were sampled by Weber-Ingenieure $\mathrm{GmbH}$ (Pforzheim, Germany) from the concrete surfaces with a sterile spatula, transferred to a sterile $50 \mathrm{~mL}$ tube, and stored at $4{ }^{\circ} \mathrm{C}$ for not longer than $48 \mathrm{~h}$ before inoculation in liquid media.

\section{SOB enrichment and cultivation}

Four culture media, differing in energy source and $\mathrm{pH}$, were applied to cultivate a variety of SOB communities. DSMZ medium 35 (Acidithiobacillus thiooxidans medium) and DSMZ medium 68 (Thiobacillus neapolitanus medium) were prepared according to DSMZ instructions (http:// www.dsmz.de/home.html). DSMZ medium 35 (pH 4.5) contained elemental sulfur and DSMZ medium $68(\mathrm{pH} 6.0$ and 8.0) provided with $\mathrm{Na}_{2} \mathrm{~S}_{2} \mathrm{O}_{3}$ as only energy sources. The other two media were prepared as described by Starosvetsky et al. [13]: ATCC medium \#125 (pH 4.1) with elemental sulfur and Thiobacillus medium ( $\mathrm{pH}$ 4.1) with $\mathrm{Na}_{2} \mathrm{~S}_{2} \mathrm{O}_{3}$ as sulfur sources. The enrichment of SOB in specific liquid media was performed as previously described [12]. All enrichment cultures that exhibited a significant $\mathrm{pH}$ decrease were transferred to corresponding solid media (agar concentration $1.5 \%$ ). The colonies were separated according to their different morphologies and streaked onto fresh solid media until pure cultures were obtained after three repetitions. Pure cultures were sequenced while the microbial diversity of the enriched cultures was additionally analyzed by PCR-DGGE. Figure 2 graphically summarizes the applied steps for sample processing.

\section{PCR amplification of the 16S rRNA gene}

For the identification of SOB pure cultures, colony PCRs were carried out using universal bacterial primers $27 \mathrm{f}$ (5'-AGA GTT TGA TCM TGG CTC AG-3') and 1492r (5'-TAC GGY TAC CTT GTT ACG ACT T-3' [14]) amplifying the nearly full-length $16 \mathrm{~S}$ rRNA gene. For DGGE analysis of the mixed SOB cultures, a 16S rRNA gene fragment ( $\sim 550 \mathrm{bp})$ was amplified using bacterial primers 27f and 517r (5'-GTA TTA CCG CGG CTG CTG GC-3' [15]), with the forward primer containing a GC-clamp (40 bp) at the 5'end (5'-CGC CCG CCG CGC CCC GCG CCC GTC CCG CCG CCG CCC CCG CCC CGG-3' [16]). PCR conditions for the primers 27f/
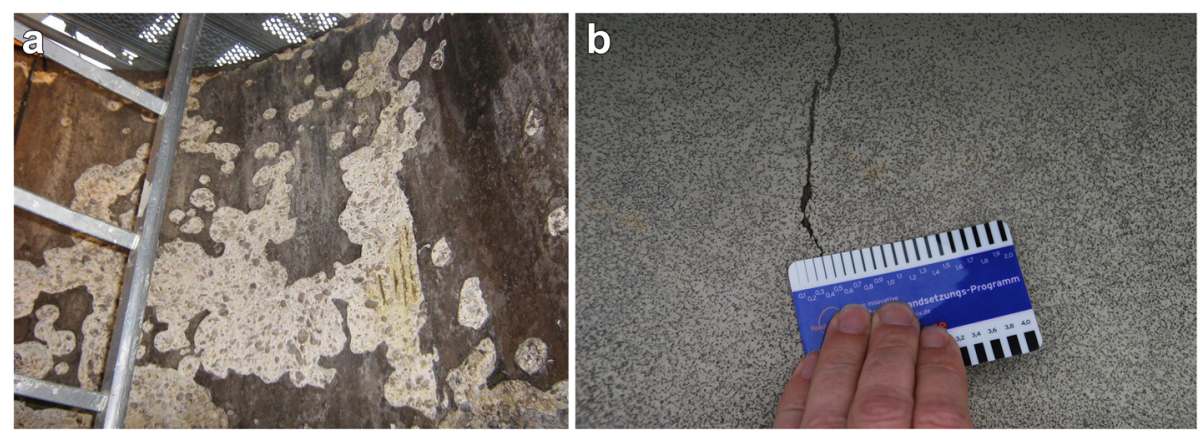

Fig. 1 a Digester headspace with severe concrete corrosion. $\mathbf{b}$ Cracks (up to $0.4 \mathrm{~mm}$ ) on the outside of a digester manhole-pit 
Table 1 Design characteristics of the six digesters A-F

\begin{tabular}{llllllll}
\hline Dg & Year of construction & WWTP PE & $\begin{array}{l}\text { Digester volume } \\
{\left[\mathrm{m}^{3}\right]}\end{array}$ & $\mathrm{RT}[\mathrm{d}]$ & $\begin{array}{l}\text { Operating temperature } \\
{\left[{ }^{\circ} \mathrm{C}\right]}\end{array}$ & $\begin{array}{l}\text { Sulfate in drilling dust } \\
\text { headspace [\% w/w] }\end{array}$ & $\begin{array}{l}\text { Sulfate in drilling dust } \\
\text { sludge zone [\% w/w] }\end{array}$ \\
\hline A & 1969 & 110,000 & 1,100 & 18 & 38 & 1.2 & 0.1 \\
B & 1974 & 83,000 & 1,150 & 25 & 37 & 0.5 & 0.4 \\
C & 1980 & 83,000 & 1,000 & 27 & 38 & 0.4 & 0.3 \\
D & 1990 & 30,000 & 2,000 & 35 & 40 & n.d. $^{\text {a }}$ & n.d. $^{\text {a }}$ \\
E & 1963 & 10,000 & 320 & 60 & $30-33$ & 0.7 & 0.5 \\
F & 1982 & 94,500 & 2,100 & 35 & 39 & 0.6 & 0.2
\end{tabular}

Dg Digester, WWTP PE Wastewater Treatment Plant Population Equivalent, RT Retention Time, ${ }^{a}$ not determined

$1492 \mathrm{r}$ and $27 \mathrm{f} / 517 \mathrm{r}$ included an initial denaturation at $95{ }^{\circ} \mathrm{C}$ for $2 \mathrm{~min}, 30$ cycles of denaturation at $95{ }^{\circ} \mathrm{C}$ for $30 \mathrm{~s}$, annealing at $55^{\circ} \mathrm{C}$ for $30 \mathrm{~s}$, elongation at $95{ }^{\circ} \mathrm{C}$ for $30 \mathrm{~s}$ and final elongation at $72{ }^{\circ} \mathrm{C}$ for $5 \mathrm{~min}$. PCR primers were obtained from Eurofins MWG Operon (Ebersberg, Germany). PCR was carried out with a primus 96 cycler (PeqLab Biotechnologie GmbH, Erlangen, Germany) using GoTaq(R) G2 Hot Start Colorless Master Mix (Promega GmbH, Mannheim, Germany) according to manufacturer's instructions.

\section{DGGE analysis}

SOB-diversity studies in mixed cultures were performed with DGGE using $15 \mu \mathrm{l}$ of the 550 bp PCR product. Separation was carried out with a $6 \%(\mathrm{w} / \mathrm{v})$ polyacrylamide gel using the DCode ${ }^{\mathrm{TM}}$ Universal Mutation Detection System (Bio-Rad Laboratories, Munich, Germany). A denaturing gradient from 20 to $80 \%$ was used (100\% denaturing solution defined as $7 \mathrm{M}$ urea and $40 \%(\mathrm{v} / \mathrm{v})$ formamide). Electrophoresis was performed at $55{ }^{\circ} \mathrm{C}$ for $16.5 \mathrm{~h}$ at a constant voltage of $60 \mathrm{~V}$. The polyacrylamide gels were stained with ethidium bromide $(0.5 \mu \mathrm{g} / \mathrm{mL})$ for $20 \mathrm{~min}$, rinsed with Milli-Q-water (Millipore, Bedford, USA), documented under UV-light (312 nm), and the dominant bands cut out with a sterile scalpel. The DNA was eluted in sterile Milli-Q water $\left(24 \mathrm{~h}, 37^{\circ} \mathrm{C}\right)$ and reamplified using the primers $27 \mathrm{f}$ and $517 \mathrm{r}$ without GCclamp.

\section{S rRNA sequencing}

Purified PCR products (innuPREP DOUBLEpure Kit, Analytik Jena, Jena, Germany) were sequenced by Eurofins MWG Operon (Ebersberg, Germany). Sequences were assembled with Geneious 7.1.7 (http://www.geneious.com), analyzed with ENA (European Nucleotide Archive) sequence search (http://www.ebi.ac.uk/ena/search), and aligned with SINA 1.2.11 [17]. Phylogenetic analyses were performed with MEGA6 [18]. Phylogenetic trees of nearly full length and $16 \mathrm{~S}$ rRNA gene fragments were calculated based on the maximum composite likelihood method with 2,000 bootstrap replications $(n=2,000)$.

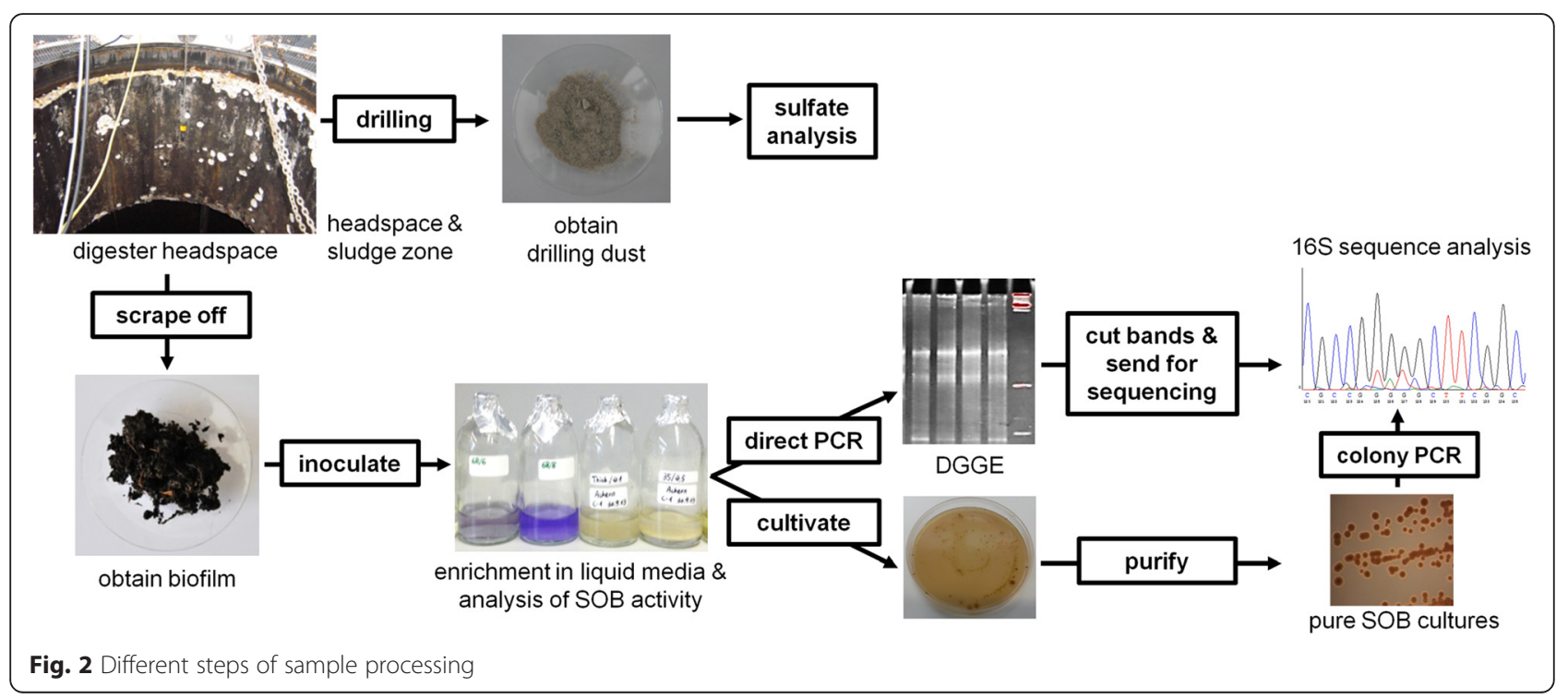


Sequences obtained from pure cultures and DGGE bands were submitted to the European Nucleotide Archive (http://www.ebi.ac.uk/ena) to get accession numbers.

\section{SOB activity of mixed and pure cultures}

Sulfuric acid production by SOB was measured under laboratory conditions via $\mathrm{pH}$ and sulfate monitoring. The $\mathrm{pH}$ was consistently tracked in all liquid cultures under sterile conditions using $\mathrm{pH}$ indicator strips (MColorpHast $^{\mathrm{m}}$, Merck Millipore, Billerica, USA), as its decline served as an indicator for SOB activity and growth. The sulfate concentration was measured in selected mixed cultures (batch cultures) after incubation of 6 to 22 days (see Table 2). Sulfate measurements were carried out in the inoculated DSMZ medium 35 with elemental sulfur as the only energy source following German Standard Methods for the examination of water, wastewater and sludge [19].

A long-term sulfate measurement for 42 days in batch-configuration (DSMZ medium 35), monitored the BSA production of isolate DgE-1 (99 \% similarity with $A$. thiooxidans, LN864656).

\section{In-situ SOB activity monitoring}

To gain information about the SOB activity in-situ, the sulfate content on the digester concrete wall was determined (Table 1). One concrete composite sample consisting of three bores was taken from the headspace and the sludge zone from every digester showing characteristic corrosion damage patterns (washed out concrete surface). The concrete was sampled in form of drilling dust in a depth of $0-40 \mathrm{~mm}$ using a hollow drill ( $25 \mathrm{~mm}$ diameter) by Weber-Ingenieure GmbH (Pforzheim, Germany). For

Table $2 \mathrm{pH}$ and sulfate concentration measurements

\begin{tabular}{|c|c|c|c|c|}
\hline Digester & Sample No. & $\begin{array}{l}\text { Incubation } \\
\text { time }[d]\end{array}$ & $\mathrm{pH}$ value & $\begin{array}{l}\text { Final sulfate } \\
\text { concentration } \\
\text { [mmol/L] }\end{array}$ \\
\hline $\bar{A}$ & 1 & 13 & 2.0 & 14 \\
\hline A & 2 & 13 & 2.0 & 16 \\
\hline B & 3 & 14 & 2.0 & 14 \\
\hline B & 4 & 14 & 2.0 & 21 \\
\hline $\mathrm{D}$ & 5 & 14 & 2.0 & 19 \\
\hline$D$ & 6 & 22 & 1.5 & 30 \\
\hline $\mathrm{D}$ & 7 & 14 & 1.5 & 52 \\
\hline E & 8 & 21 & 2.0 & 12 \\
\hline$E$ & 9 & 14 & 2.0 & 17 \\
\hline $\mathrm{E}$ & 10 & 6 & 1.5 & 33 \\
\hline$E$ & 11 & 6 & 1.5 & 50 \\
\hline$E$ & 12 & 8 & 1.0 & 87 \\
\hline F & 13 & 14 & 2.0 & 10 \\
\hline$F$ & 14 & 14 & 2.0 & 11 \\
\hline $\mathrm{F}$ & 15 & 14 & 2.0 & 13 \\
\hline
\end{tabular}

Analyses were performed in selected mixed enriched batch cultures after 6-22 days of incubation. DSMZ medium 35 (A. thiooxidans medium) with an initial $\mathrm{pH}$ value of 4.5 and elemental sulfur as sole energy source was used as culture medium sulfate measurements, the drilling dust samples were thermally disintegrated at $80{ }^{\circ} \mathrm{C}$ and $15 \%(\mathrm{v} / \mathrm{v})$ hydrochloric acid followed by a photometrical analysis at $436 \mathrm{~nm}$ (Nanocholor 500 D, Macherey und Nagel, Germany). The analysis was performed by the laboratory "Dr. Michael Figgemeier-Baustoffanalyse \& Bauphysik" (Ludwigsburg, Germany).

\section{Results}

\section{Enriched SOB cultures}

The highest SOB diversities were obtained in Thiobacillus medium ( $\mathrm{pH} 4.1$ ) and DSMZ medium 68 ( $\mathrm{pH} 6.0$ and 8.0). The diversity assessment by PCR-DGGE with the mixed liquid cultures revealed different phylogenetic diversities in the six analyzed sludge digesters (Fig. 3). 12 taxonomically distinct genera were found with PCR-DGGE. Highest diversities were observed in digesters $\mathrm{D}$ and $\mathrm{E}$, with five and eight different genera, respectively. A lower microbial diversity was observed in the remaining four digesters. Eight of the 12 genera are affiliated with sulfur-oxidizing bacteria and are marked in bold in the phylogenetic tree (Fig. 3). Within the liquid cultures of all six digesters (Dg A-F), the detected sulfur oxidizers were closely related to different Thiomonas spp. (Dg A, B, D, E, F), Delftia sp. (Dg D and E), Hyphomicrobium sp. (Dg E), Ancylobacter sp. (Dg D), Paracoccus sp. (Dg A and C), Mesorhizobium sp. (Dg E), different Acidithiobacillus spp. (Dg D and E), and Alicyclobacillus sp. (Dg B and E). The other four genera Sphingomonas (Dg E), Stenotrophomonas (Dg D), Sphingobacterium (Dg C), and Moraxella (Dg E) are non-SOB and might not be related to the sulfur cycle.

Sulfate concentration measurements of specific mixed liquid cultures were used to analyze BSA production capacity (Table 2). The presence and laboratory-confirmed activity of different SOB was considered as BSA corrosion potential. For sulfate measurements, DSMZ medium 35 was used, because elemental sulfur was the only provided sulfur compound leading to an initial sulfate concentration lower than $0.5 \mu \mathrm{mol} / \mathrm{L}$. The microbial community in this specific liquid medium, inoculated with biofilm from Dg E, reduced the $\mathrm{pH}$ from 4.5 to 1.0-1.5 (Table 2, No. 10-12) after six (No. 10 and 11) and eight days (No. 12) of incubation, respectively, while the sulfate concentration increased to $33-87 \mathrm{mmol} / \mathrm{L}$ indicating high sulfuric acid production. The main acid producers were identified as Acidithiobacillus spp. and Thiomonas spp. (Figs. 3 and 4). Dg D showed a high sulfuric acid production, too, and liquid cultures No. 6 and 7 reached sulfate concentrations of $30 \mathrm{mmol} / \mathrm{L}$ and $52 \mathrm{mmol} / \mathrm{L}$ after 22 days and 14 days of incubation, respectively. The sulfate concentrations in the other analyzed cultures fluctuated between $10 \mathrm{mmol} /$ $\mathrm{L}$ and $21 \mathrm{mmol} / \mathrm{L}$ showing a lower BSA production, with 


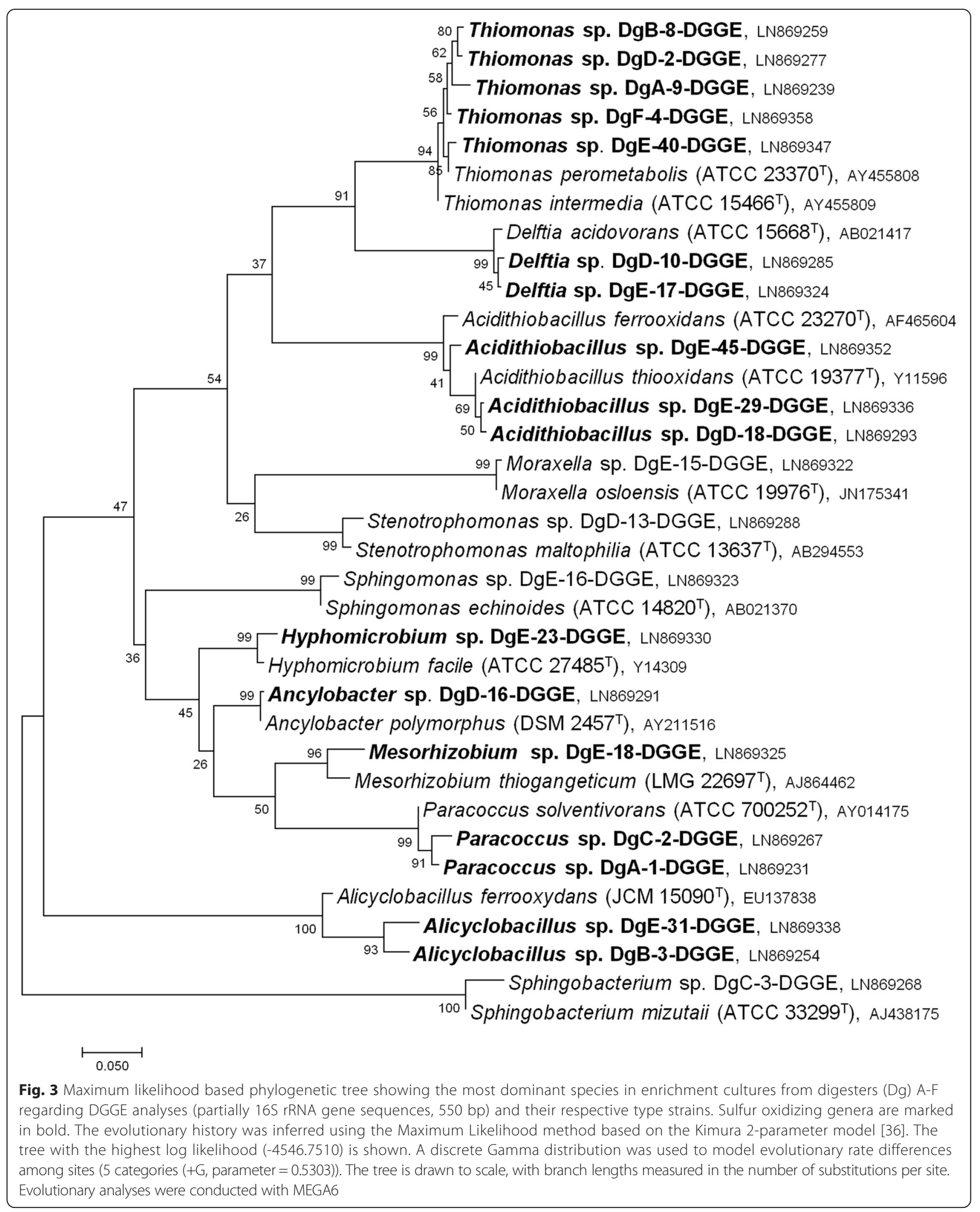




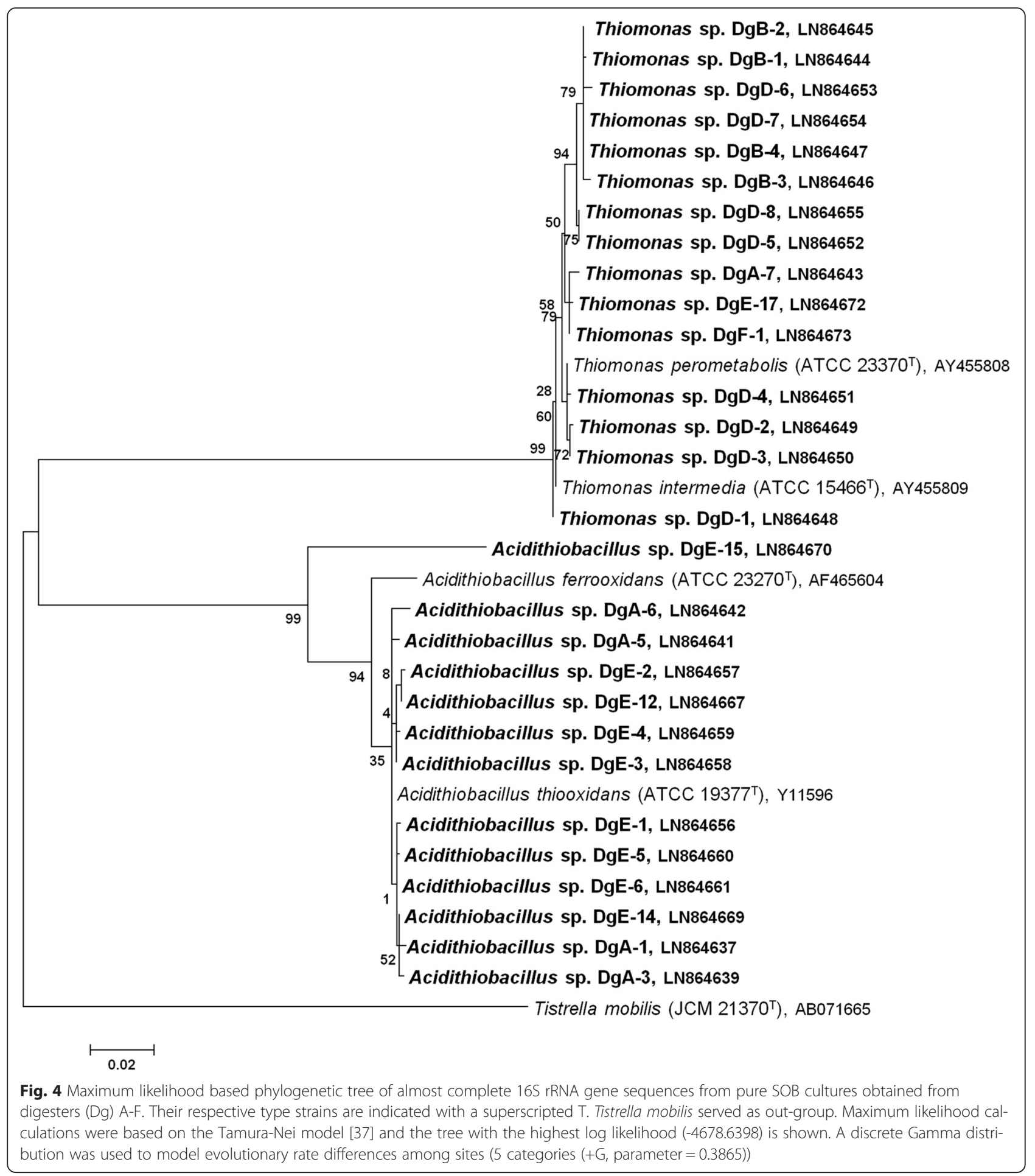

the lowest $(10-13 \mathrm{mmol} / \mathrm{L})$ found in digester $\mathrm{F}$, where only the NSOB Thiomonas sp. was detected (Figs. 3 and 4).

Pure SOB cultures

Enrichments that exhibited a significant $\mathrm{pH}$ decrease were streaked on their corresponding solid medium to isolate pure SOB. For isolation, DSMZ medium 68
(pH 6.0) and Thiobacillus medium ( $\mathrm{pH} 4.1$ ) showed the best results. Approximately 40 isolates that showed a $\mathrm{pH}$ decline on the agar medium (visible due to $\mathrm{pH}$ indicators) were identified by $16 \mathrm{~S}$ rRNA gene sequence analysis. Three sulfur oxidizing species, associated with concrete corrosion, were closely related to Acidithiobacillus thiooxidans, Thiomonas intermedia and Thiomonas 
perometabolis. Their phylogenetic relation is displayed in Fig. 4. In Dg A and E, the acidophilic Acidithiobacillus thiooxidans. and neutrophilic Thiomonas spp. were detected, whereas in Dg B, D and F only neutrophilic Thiomonas spp. were identified.

By applying different media, varying in initial $\mathrm{pH}$ and sulfur components, a variety of $\mathrm{SOB}$ species detected by DGGE in mixed culture (Fig. 3) was obtained. Enrichment and cultivation of mixed cultures worked best in DSMZ medium 68 and Thiobacillus medium. For cultivation of pure $A$. thiooxidans, best growth occurred in DSMZ medium 35 ( $\mathrm{pH} 4.5$ ) with elemental sulfur as sole energy source. After an incubation period of two weeks, A. thiooxidans reduced the $\mathrm{pH}$ in DSMZ medium 35 from 4.5 to 0.5 indicating a high sulfuric acid production and BSA corrosion potential. For cultivation of pure Thiomonas spp., media with $\mathrm{Na}_{2} \mathrm{~S}_{2} \mathrm{O}_{3}$ and initial $\mathrm{pH}$ values of 4.0-6.0 showed best results (DSMZ 68 and Thiobacillus medium). Thiomonas spp. reduced the $\mathrm{pH}$ within the used DSMZ medium 68 from 6.0 to 2.5 after two weeks of incubation, also revealing a high acid production potential.

A long term sulfate measurement over 42 days in DSMZ medium 35, inoculated with $A$. thiooxidans isolate DgE-1 (LN864656; see Fig. 4) from digester E, reached a sulfate concentration of more than $417 \mathrm{mmol} / \mathrm{L}$ (Fig. 5). When comparing the sulfuric acid production of pure A. thiooxidans with the mixed enriched cultures, a similar trend was observed within the first days of incubation (Fig. 5 and Table 2). After six days of incubation, the sulfate concentration in the mixed enrichments $(33-50 \mathrm{mmol} / \mathrm{L})$ was comparable to the sulfate concentration measured in the pure culture
( $21 \mathrm{mmol} / \mathrm{L})$. After an incubation period of 14 days, the sulfuric acid production in pure $A$. thiooxidans was significantly higher $(130 \mathrm{mmol} / \mathrm{L})$ than in the mixed cultures $(10-52 \mathrm{mmol} / \mathrm{L})$, and after 21 days, the difference between the mixed enrichments $(12-30 \mathrm{mmol} / \mathrm{L})$ and the pure $A$. thiooxidans $(\sim 208 \mathrm{mmol} / \mathrm{L})$ was even greater.

\section{In-situ BSA activity in sludge digester}

All analyzed digesters (A-C and E-F) showed a higher sulfate content on the concrete surface of the digester headspace than in the sludge zone (Table 1). The highest difference was observed in Dg A, where the sulfate concentration in the headspace $(1.2 \% \mathrm{w} / \mathrm{w})$ was more than ten-times higher than in the sludge zone $(0.1 \% \mathrm{w} / \mathrm{w})$, potentially resulting from the activity of the ASOB $A$. thiooxidans found in this digester (Fig. 4).

\section{Discussion}

Cultivation and isolation of active SOB communities

SOB within the biofilm samples were specifically enriched to test their sulfuric acid production activity. Although cultivation dependent techniques may not be appropriate to draw a comprehensive picture of the microbial community, they are the only and still powerful method to investigate the capability of sulfuric acid production and BSA corrosion potential under defined conditions. By enrichment in specific media, different SOB species were purified (Fig. 4). A variety of BSA related bacteria were identified in the liquid cultures (Fig. 3), and their sulfuric acid production capacity was demonstrated under laboratory conditions (10-433 mmol/L).

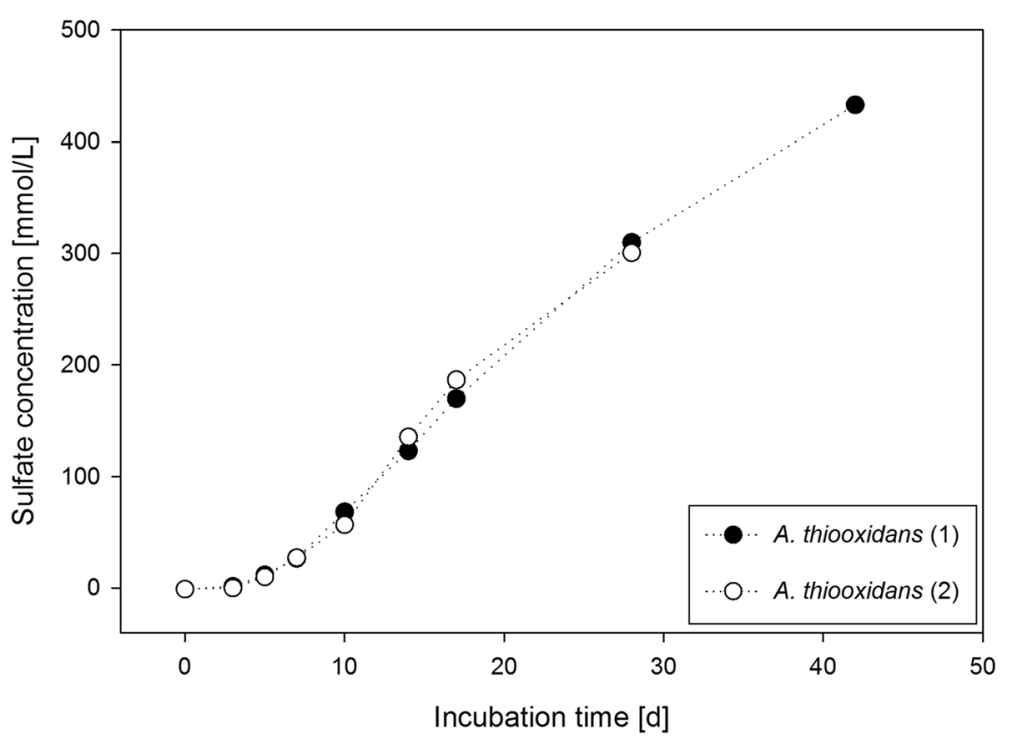

Fig. 5 Final sulfate concentration in pure A. thiooxidans liquid batch culture (isolate Dg E-1) over 42 days. DSMZ medium 35 with an initial pH value of 4.5 and elemental sulfur as sole energy source was used. Error of the method was indicated by the manufacturer with $10 \%$ 
For SOB purification different media with elemental sulfur and sodium thiosulfate as only energy sources were applied to obtain a high SOB diversity. Thiosulfate, the most frequently used substrate for $\mathrm{SOB}$ cultivation, is, in contrast to elemental sulfur, highly water soluble and stable over a broad $\mathrm{pH}$ range [20]. In addition, autotrophic media were utilized as the main contributors to corrosion, e.g., Acidithiobacillus spp. and Thiomonas spp., are known obligate or facultative autotrophs. Furthermore, such media suppress the growth of unwanted heterotrophic bacteria, which are most likely dominant in the biofilm sample. One major problem in obtaining selective enrichment of chemolithoautotrophic organisms is the contamination through organic compounds [20] resulting in the detection of non-SOB species. Sources for heterotrophic contaminants are i) contaminated water or chemicals used for media preparation, ii) trace amounts of soluble organic material in almost all agar brands, and iii) secretion of organic compounds by obligate chemolithotrophs [20]. Apart from the identification of a few heterotrophic non-SOB species, the application of selective culture media allowed to specifically enrich the organisms of interest (Figs. 3 and 4). This shows the potential of highly selective media as the desired organisms grew best under these conditions. However, a more comprehensive picture of the SOB diversity within the liquid media was drawn by PCRDGGE (Fig. 3). It has to be mentioned, that only the combination of cultivation dependent and -independent (PCR-DGGE) techniques revealed a variety of taxonomically different sulfur oxidizers that can be classified in acidophilic and neutrophilic sulfur oxidizing bacteria (ASOB and NSOB) as well as non-SOB.

\section{Acidophilic sulfur oxidizing bacteria (ASOB)}

Acidithiobacillus spp. and/or Alicyclobacillus sp. were identified in enriched cultures of Dg A, B, D and E (Figs. 3 and 4) and are known to produce sulfuric acid from reduced sulfur compounds [21]. The identification of ASOB in the apparently neutral digester environment suggests that $\mathrm{pH}$ gradients and "acidic microniches" might be present, especially in the biofilm of the digester headspace [20].

All members of the genus Acidithiobacillus are obligate acidophiles and characterized by chemolithoautotrophic growth [20]. Pure A. thiooxidans with a growth optimum at $\mathrm{pH} 2.0-4.0$ can be cultivated in acidic media with elemental sulfur as the only nutrient $[20,22]$, as has been confirmed in this study as well. A. thiooxidans, found in Dg A, D and E, is a key organism for BSA corrosion, because it has been the most dominant species in heavily corroded concrete samples [3, 6]. A. thiooxidans can produce high amounts of sulfuric acid and grows at $\mathrm{pH}$ values as low as $0.5[6,20]$. In this study, $A$. thiooxidans produced a sulfuric acid concentration of $4 \%$ (Fig. 5). Cwalina [23] stated that biogenic $\mathrm{H}_{2} \mathrm{SO}_{4}$ in concrete pores may even reach $10 \%$.

Alicyclobacillus sp. was detected within the enrichment cultures of Dg D and E using PCR-DGGE. A few members of the genus Alicyclobacillus have been described as sulfur- and ferrous-oxidizing [24]. A study by Vupputuri et al. [25], analyzing the microbial diversity on concrete surfaces from deteriorated bridge structures, revealed that Alicyclobacillus spp. was the most dominant sulfur oxidizing acid producer that reduced the $\mathrm{pH}$ value of the culture medium from 6.7 to 2.8 .

\section{Neutrophilic sulfur oxidizing bacteria (NSOB)}

The presence of Thiomonas intermedia and Thiomonas perometabolis, obtained in pure (Fig. 4), was already described in corroded concrete samples [3, 26, 27]. A study by Wei et al. [26] using liquid cultures inoculated with corroded material from a bridge support, found T. perometabolis as the dominant acid producer.

Another NSOB, Paracoccus sp., occurred in liquid cultures of $\mathrm{Dg} \mathrm{A}$ and $\mathrm{C}$ and is known to oxidize reduced sulfur compounds (e.g., thiosulfate and elemental sulfur) to generate energy for autotrophic growth [28].

The genera Ancylobacter, Mesorhizobium, Hyphomicrobium and Delftia comprise sulfur/sulfide oxidizing species, but are not typically mentioned in the context of BSA corrosion. Growth tests with Ancylobacter aquaticus showed its ability to grow chemolithoautrotrophically when thiosulfate was provided as only energy source [29]. For Mesorhizobium thiogangeticum, originally identified in rhizosphere soil, chemolithoautotrophic growth was observed with $\mathrm{Na}_{2} \mathrm{~S}_{2} \mathrm{O}_{3}$ and $\mathrm{S}^{0}$ [30]. Hyphomicrobium sp. is known for its oxidation of hydrogen sulfide to elemental sulfur [31]. SOB, isolated from a rice field soil, were closely related to Delftia sp. [32] indicating its ability for sulfur-oxidation.

\section{Non-SOB species}

Other heterotrophic microorganisms not commonly associated with sulfur oxidation and thus termed non-SOB, e.g., Sphingobacterium sp., Sphingomonas sp., and Stenotrophomonas sp., were detected in this study as well. The identification of heterotrophic non-SOB in the enrichment cultures was probably due to their presence in the original biofilm. A contamination with organic residues from the biofilm sample may have enabled the growth of heterotrophic non-SOB in the culture media. Furthermore, many obligate chemolithotrophic sulfur oxidizers produce organic substances that could be subsequently utilized by heterotrophs [20] leading to the growth of non-SOB species. However, the non-SOB detected in this study might still play an important role because their presence was already reported in several samples of corroded concrete 


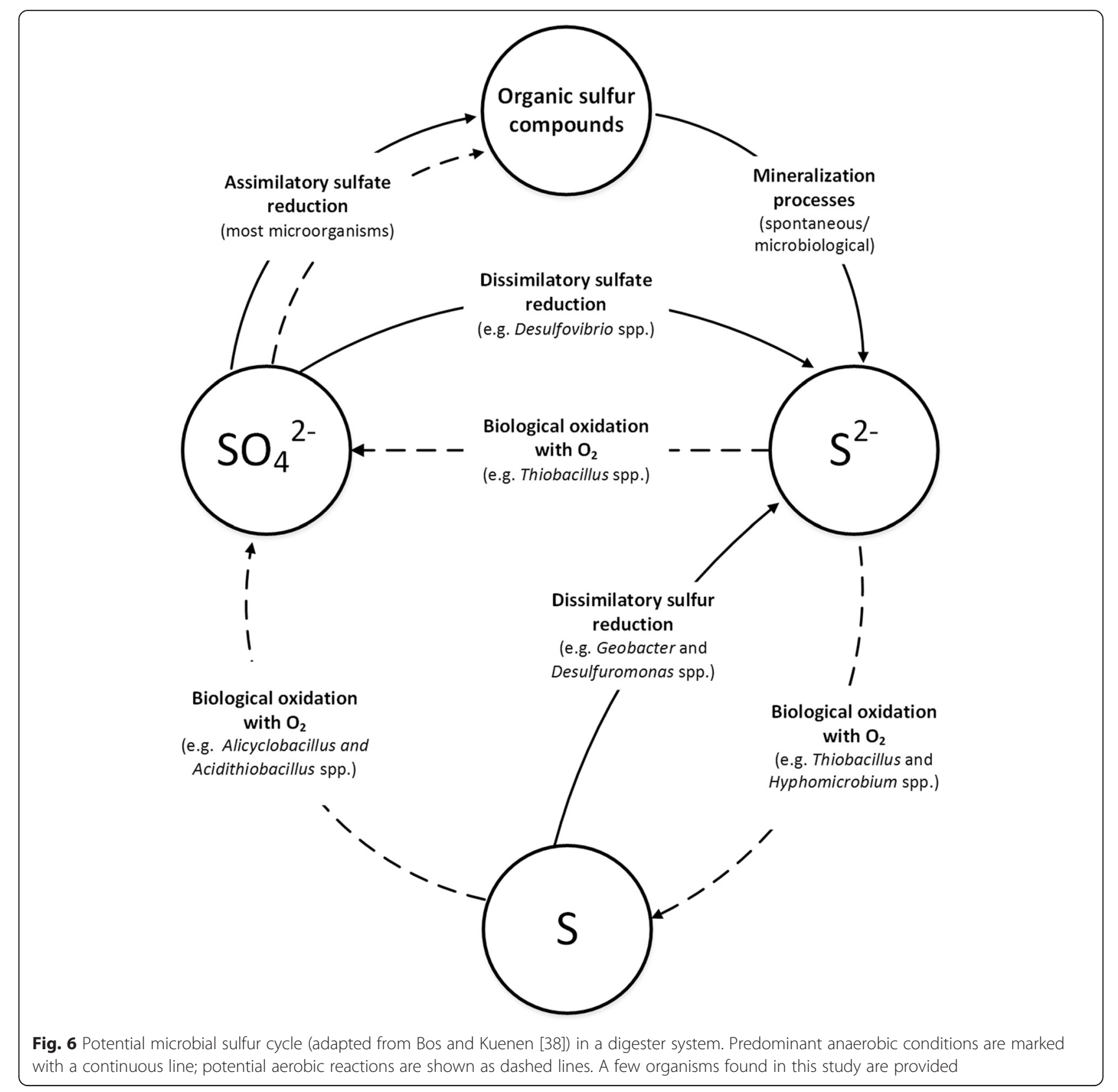

originating from different sewer pipes. SOB might interact with non-SOB in the biofilm matrix where excreted metabolites could serve as nutrients for non-SOB or vice versa. Sphingobacteriales, for instance, are dominant in microbial induced concrete corrosion layers [2] and Sphingomonas sp. was detected in corroded sewer pipes above the water level [33]. Stenotrophomonas maltophilia was found in slightly corroded concrete material but also observed in the surrounding of the steel bar [3, 33].

Oxygen availability and BSA corrosion in sludge digesters In contrast to sewer pipes, oxygen availability in sludge digesters is rather limited [11,34] and thus, crucial for
BSA corrosion. However, in this study typical BSA corrosion damage patterns, characterized by washed out concrete surfaces, were observed in the headspace of several digesters (see Fig. 1), indicating SOB activity resulting in BSA production and corrosion. Thus, oxygen carriers must be at least available in small patches fostering the growth of sulfur-oxidizing communities. Many sulfur oxidizers can grow in niches, where sulfide and oxygen coexist [20]. When oxygen, even at low levels, is available, sulfur oxidizers can spontaneously oxidize sulfide. Very high turnover rates of sulfide were reported even at extremely low concentrations of sulfide and oxygen $\left(<10^{-6} \mathrm{mM}\right)$ [20]. It is supposed that oxygen 
availability in microniches might be sufficient for SOB activity and enable the oxidation of sulfur compounds to sulfate or sulfuric acid. Thermodynamically, oxidation of sulfuric compounds is always favored compared to the oxidation of methane, as is applied in biological in-situ desulfurization in digesters.

The predominant anaerobic conditions in a sludge digester promote the growth of SRB communities and consequently sulfur/sulfate reduction (continuous lines, Fig. 6). In case of local oxygen availability, especially in the digester headspace biofilm, it is assumed that sulfur/sulfide oxidation by SOB takes place (dashed lines, Fig. 6).

Under anaerobic conditions, sulfate, which is commonly found in sewage sludge [11], can be reduced to sulfide $\left(\mathrm{S}^{2-}\right)$ by anaerobic SRB (e.g., Desulfovibrio spp.). $\mathrm{S}^{2-}$ can be abiotically or biotically converted by, e.g., Hyphomicrobium spp., to elemental sulfur [31, 35]. Elemental sulfur can either be further oxidized by other SOB species (e.g., Alicyclobacillus spp. , and Acidithiobacillus spp.) in case of oxygen availability, or might be reconverted under anaerobic conditions to sulfide by SRB such as Geobacter spp. The concurrent detection of SRB and SOB in sludge digesters [12] indicates that these two groups might interact to oxidize and reduce sulfur compounds. Increased sulfate concentrations on the concrete wall of the digester headspace (compared to the sludge zone) provided further evidence for biological sulfur oxidation in the headspace. However, only a steady sulfur/sulfide oxidation over years to decades could result in the characteristic corrosion damage pattern as shown in Fig. 1.

\section{Conclusions}

This study revealed the presence of different SOB species on the headspace concrete wall of six sludge digesters and showed their capability to produce BSA under laboratory conditions. The identified SOB species potentially contribute to BSA corrosion in sludge digesters, especially as elevated sulfate concentrations on the concrete walls of the digester headspace were measured in-situ. However, further investigations on the availability of oxygen carriers, sulfide turnover rates and SOB activity in digester systems are vital to finally draw a conclusive picture about the BSA production in situ.

\section{Acknowledgements}

The authors would like to thank Weber-Ingenieure GmbH for providing pictures of the digester headspace, biofilm and drilling dust samples. LisaMarie Rempe is acknowledged for technical assistance.

\section{Funding}

This study was funded by the Bundesministerium für Wirtschaft und Energie (BMWi), Zentrales Innovationsprogramm Mittelstand, ZIM-Kooperationsprojekt (grant number KF2990501SA2). This work was supported by the German Research Foundation (DFG) and the Technical University of Munich (TUM) in the framework of the Open Access Publishing Program.

\section{Authors' contributions}

BeH drafted the manuscript, designed and carried out the biodegradation experiments. $\mathrm{BH}, \mathrm{JD}$, and $\mathrm{KK}$ reviewed and edited the manuscript. EM conceived of the study and helped to review the manuscript. All authors read and approved the final manuscript.

\section{Competing interests}

The authors declare that they have no competing interests.

Ethics approval and consent to participate

Not applicable.

Received: 28 February 2016 Accepted: 8 July 2016

Published online: 18 July 2016

\section{References}

1. Hewayde E, Nehdi M, Allouche E, Nakhla G. Effect of mixture design parameters and wetting-drying cycles on resistance of concrete to sulfuric acid attack. J Mater Civil Eng. 2007;19(2):155-63.

2. Cayford BI, Dennis PG, Keller J, Tyson GW, Bond PL. High-throughput amplicon sequencing reveals distinct communities within a corroding concrete sewer system. Appl Environ Microbiol. 2012;78(19):7160-2.

3. Okabe $\mathrm{S}$, Odagiri M, Ito $\mathrm{T}$, Satoh $\mathrm{H}$. Succession of sulfur-oxidizing bacteria in the microbial community on corroding concrete in sewer systems. Appl Environ Microbiol. 2007;73(3):971-80.

4. Roberts DJ, Nica D, Zuo G, Davis JL. Quantifying microbially induced deterioration of concrete: initial studies. Int Biodeter Biodegr. 2002;49(4): 227-34.

5. Bielefeldt A, Gutierrez-Padilla MGD, Ovtchinnikov S, Silverstein J, Hernandez M. Bacterial kinetics of sulfur oxidizing bacteria and their biodeterioration rates of concrete sewer pipe samples. J Environ Eng. 2009;136(7):731-8.

6. Diercks M, Sand W, Bock E. Microbial corrosion of concrete. Experientia. 1991;47(6):514-6.

7. Wei S, Jiang Z, Liu H, Zhou D, Sanchez-Silva M. Microbiologically induced deterioration of concrete: a review. Braz J Microbiol. 2013; 44(4):1001-1007.

8. O'Connell M, Mcnally C, Richardson MG. Biochemical attack on concrete in wastewater applications: a state of the art review. Cem Concr Compos. 2010;32(7):479-85

9. Wells T, Melchers RE. Modelling concrete deterioration in sewers using theory and field observations. Cem Concr Res. 2015;77:82-96.

10. Vollertsen J, Nielsen AH, Jensen HS, Wium-Andersen T, Hvitved-Jacobsen T. Corrosion of concrete sewers - the kinetics of hydrogen sulfide oxidation. Sci Total Environ. 2008;394(1):162-70.

11. Appels L, Baeyens J, Degrève J, Dewil R. Principles and potential of the anaerobic digestion of waste-activated sludge. Prog Energy Combust Sci. 2008:34(6):755-81.

12. Huber B, Drewes J, Lin K, König R, Müller E. Revealing biogenic sulfuric acid corrosion in sludge digesters: detection of sulfur-oxidizing bacteria within full-scale digesters. Water Sci Technol. 2014;70(8):1405-11.

13. Starosvetsky J, Zukerman U, Armon RH. A simple medium modification for isolation, growth and enumeration of Acidithiobacillus thiooxidans (syn. Thiobacillus thiooxidans) from water samples. J Microbiol Meth. 2013; 92(2):178-82.

14. Lane DJ. 16S/23S rRNA sequencing. In: Nucleic Acid Techniques in Bacterial Systematics (E. Stackebrandt \& M. Goodfellow, eds). New York, USA: Wiley; 1991. pp. 115-175.

15. Furushita M, Shiba T, Maeda T, Yahata M, Kaneoka A, Takahashi Y, Torii K, Hasegawa T, Ohta M. Similarity of tetracycline resistance genes isolated from fish farm bacteria to those from clinical isolates. Appl Environ Microbiol. 2003;69(9):5336-42.

16. Muyzer G, De Waal EC, Uitterlinden AG. Profiling of complex microbial populations by denaturing gradient gel electrophoresis analysis of polymerase chain reaction-amplified genes coding for 165 rRNA. Appl Environ Microbiol. 1993:59(3):695-700.

17. Pruesse E, Peplies J, Glöckner FO. SINA: accurate high-throughput multiple sequence alignment of ribosomal RNA genes. Bioinformatics. 2012;28(14): 1823-9.

18. Tamura K, Stecher G, Peterson D, Filipski A, Kumar S. MEGA6: molecular evolutionary genetics analysis version 6.0. Mol Biol Evol. 2013;30(12):2725-9. 
19. DEV. Deutsche Einheitsverfahren zur Wasser-, Abwasser- und Schlammuntersuchung (German standard methods for examination of water, wastewater and sludge). Weinheim: Wiley-VCH; 2016.

20. Robertson LA, Kuenen JG. The genus Thiobacillus. Prokaryotes. 2006:5:812-27.

21. Rohwerder T, Sand W. Oxidation of inorganic sulfur compounds in acidophilic prokaryotes. Eng Life Sci. 2007;7(4):301-9.

22. Yin H, Zhang X, Li X, He Z, Liang Y, Guo X, Hu Q, Xiao Y, Cong J, Ma L. Wholegenome sequencing reveals novel insights into sulfur oxidation in the extremophile Acidithiobacillus thiooxidans. BMC Microbiol. 2014;14(1):179.

23. Cwalina B. Biodeterioration of concrete. Arch Civil Eng Environ. 2008;4:133-40.

24. Guo X, You X-Y, Liu L-J, Zhang J-Y, Liu S-J, Jiang C-Y. Alicyclobacillus aeris sp. nov., a novel ferrous-and sulfur-oxidizing bacterium isolated from a copper mine. Int J Syst Evol Micr. 2009;59(10):2415-20.

25. Vupputuri S, Wilber GG, Nasrazadani PS, Ramsey PJD. Characterization and mediation of microbial deterioration of concrete bridge structures. Final report. 2013.

26. Wei S, Sanchez M, Trejo D, Gillis C. Microbial mediated deterioration of reinforced concrete structures. Int Biodeter Biodegr. 2010;64(8):748-54.

27. Gomez-Alvarez V, Revetta RP, Santo Domingo JW. Metagenome analyses of corroded concrete wastewater pipe biofilms reveal a complex microbial system. BMC Microbiol. 2012;12(1):1.

28. Kelly DP, Rainey FA, Wood AP. The genus Paracoccus. The Prokaryotes, 2006; 5:232-49.

29. Stubner S, Wind T, Conrad R. Sulfur oxidation in rice field soil: activity, enumeration, isolation and characterization of thiosulfate-oxidizing bacteria. Syst Appl Microbiol. 1998;21(4):569-78.

30. Ghosh W, Roy P. Mesorhizobium thiogangeticum sp. nov., a novel sulfuroxidizing chemolithoautotroph from rhizosphere soil of an Indian tropical leguminous plant. Int J Syst Evol Micr. 2006;56(1):91-7.

31. Mohapatra BR, Gould WD, Dinardo O, Koren DW. An overview of the biochemical and molecular aspects of microbial oxidation of inorganic sulfur compounds. CLEAN - Soil, Air, Water. 2008;36(10-11):823-9.

32. Graff A, Stubner S. Isolation and molecular characterization of thiosulfateoxidizing bacteria from an italian rice field soil. Syst Appl Microbiol. 2003; 26(3):445-52.

33. Vincke $E$, Boon N, Verstraete W. Analysis of the microbial communities on corroded concrete sewer pipes-a case study. Appl Microbiol Biotechnol. 2001;57(5-6):776-85.

34. Rasi S, Veijanen A, Rintala J. Trace compounds of biogas from different biogas production plants. Energy. 2007;32(8):1375-80.

35. Lee E, Cho K-S, Ryu H. Characterization of sulfur oxidation by an autotrophic sulfur oxidizer, Thiobacillus sp. ASWW-2. Biotechnol Bioproc E. 2000;5(1):48-52.

36. Kimura M. A simple method for estimating evolutionary rates of base substitutions through comparative studies of nucleotide sequences. J Mol Evol. 1980;16(2):111-20

37. Tamura K, Nei M. Estimation of the number of nucleotide substitutions in the control region of mitochondrial DNA in humans and chimpanzees. Mol Biol Evol. 1993;10(3):512-26.

38. Bos $\mathrm{P}$, Kuenen J. Microbiology of sulfur-oxidizing bacteria. In: Microbial corrosion, proc conf, 1983. p. 18-27.

\section{Submit your next manuscript to BioMed Central and we will help you at every step:}

- We accept pre-submission inquiries

- Our selector tool helps you to find the most relevant journal

- We provide round the clock customer support

- Convenient online submission

- Thorough peer review

- Inclusion in PubMed and all major indexing services

- Maximum visibility for your research

Submit your manuscript at www.biomedcentral.com/submit

) Biomed Central 